\title{
Protection of chimpanzees from high-dose heterologous HIV-1 challenge by DNA vaccination
}

\author{
Jean D. Boyer ${ }^{1 *}$, Kenneth E. Ugen ${ }^{2 *}$, Bin Wang ${ }^{1}$, Michael Agadjanyan ${ }^{1}$, Lori Gilbert ${ }^{1}$, \\ Mark L. Bagarazzi ${ }^{3}$, Michael Chattergoon ${ }^{1}$, Patrice Frost ${ }^{4}$, Ali Javadian ${ }^{4}$, \\ Williams V. Williams ${ }^{5}$, Yosef Refaeli ${ }^{6}$, Richard B. Ciccarelli? ${ }^{7}$, Daniel McCallus? \\ LESLIE CONEY ${ }^{7} \&$ DAVID B. WEINER ${ }^{1}$ \\ 'Department of Pathology and Laboratory Medicine, University of Pennsylvania, 505 Stellar-Chance Building, \\ 422 Curie Boulevard, Philadelphia, Pennsylvania, 19104, USA \\ ${ }^{2}$ Department of Medical Microbiology and Immunology, University of South Florida, MDC 1012901 Bruce B. \\ Downs Boulevard, Tampa, Florida, 33612, USA \\ ${ }^{3}$ Department of Pediatrics, University of Pennsylvania, 505 Stellar-Chance Building, 422 Curie Boulevard, \\ Philadelphia Pennsylvania, 19104, USA \\ ${ }^{4}$ White Sands Research Center, Coulston Foundation, 1300 Lavelle Road, Alamogordo, New Mexico, 88310, USA \\ ${ }^{5}$ Hospital of the University of Pennsylvania, 912 Stellar-Chance Building, 422 Curie Boulevard, \\ Philadelphia, Pennsylvania 19104, USA \\ ${ }^{6}$ Department of Pathology, Harvard University, LMRC-5, 221 Longwood Avenue, Boston, Massachusetts 02115, USA \\ 'Apollon Inc., 1 Great Valley Parkway, Malvern, Pennsylvania, 19355, USA \\ *These authors contributed equally to this manuscript.
}

\begin{abstract}
Novel approaches for the generation of more effective vaccines for HIV-1 are of significant importance. In this report we analyze the immunogenicity and efficacy of an HIV-1 DNA vaccine encoding env, rev and $\mathrm{gag} / \mathrm{pol}$ in a chimpanzee model system. The immunized animals developed specific cellular and humoral immune responses. Animals were challenged with a heterologous chimpanzee titered stock of HIV-1 SF2 virus and followed for $\mathbf{4 8}$ weeks after challenge. Polymerase chain reaction coupled with reverse transcription (RT-PCR) results indicated infection in the control animal, whereas those animals vaccinated with the DNA constructs were protected from the establishment of infection. These studies serve as an important benchmark for the use of DNA vaccine technology for the production of protective immune responses.
\end{abstract}

Efficacy and safety concerns remain in the field of HIV vaccine development despite extensive laboratory immunological analysis and animal testing. Although no single measure of immunity is predictive of in vivo control of viral replication, there is mounting evidence that an efficacious vaccine against HIV-1 will need to induce both cellular and humoral immune responses to control infection. In the majority of cases, the natural immune response generated against HIV-1 is incapable of preventing the eventual onset of AIDS. However, a minority of patients, termed nonprogressors, tend to share a similar immunological phenotype that includes strong antiviral cellular as well as humoral immune responses ${ }^{1}$. Patients mounting strong gp160-specific cytotoxic T lymphocyte (CTL) responses have shown a rapid reduction of acute viremia and antigenemia, and a high level of CTL activity has been associated with long-term survival ${ }^{2,3}$. In contrast, primary viremia and antigenemia were poorly controlled in patients in whom virus-specific CTL activity was low or undetectable. Furthermore, a definite CTL response has been observed in Gambian sex workers who remain seronegative as well as PCR negative for HIV-1 despite repeated exposure to HIV-1 (ref. 4, 5). High levels of antibodies, most notably neutralizing and cross-reactive neutralizing antibodies have also been observed in the serum of long-term survivors ${ }^{2}$. Stronger serological responses have been observed in mothers who do not transmit HIV-1 to their babies ${ }^{6-9}$. In general, stronger and broader immune responses have been associated with delayed disease progression and are likely to have a positive impact on limiting replication, although the ability of the immune response to affect viral replication in infected individuals remains controversial.

Recently, several groups have reported on the ability of the novel vaccine technology, designated genetic vaccination, nucleic acid vaccination or DNA vaccination to induce immune responses in vivo. Injection of cDNA expression cassettes results in in vivo expression of the encoded protein $\mathrm{s}^{\mathrm{10}-12}$ with the concomitant development of specific cellular and humoral immune responses directed against the encoded antigen $(s)^{1.3-17}$. The endogenous production of antigen by the host cell transcriptional machinery mimics aspects of live attenuated vaccines without the associated risk of potential pathogenic replication. Protective responses have been reported in several murine disease models using this technology ${ }^{18-21}$. Humoral and cellular responses have been induced to HIV-1 and SIV antigens through various applications of this technology in macaques $\mathrm{s}^{22-24}$ as well as mice ${ }^{22,25-27}$. However, the ability of this technology to induce protective responses after infection in higher nonhuman primate models has never been established ${ }^{28}$.

Chimpanzees (Pan troglodytes) provide a particularly relevant model for the evaluation of vaccines against HIV-1. The chimpanzee and human immune systems share many common features including antigenic cross-reactivity of divergent 


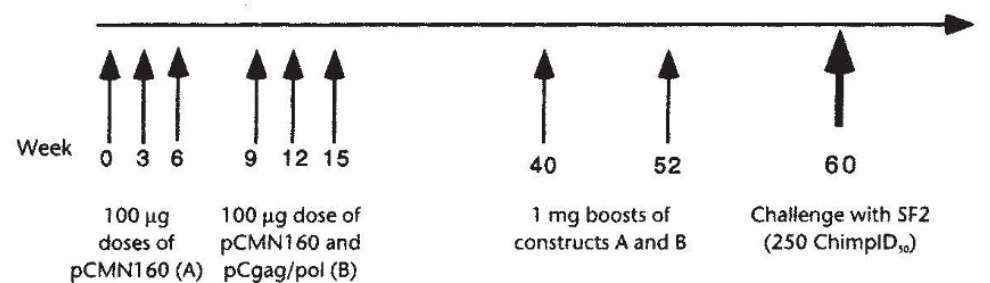

Fig. 1 Schematic of immunization protocol for chimpanzees 19, 83, 94 and 92. as virus can be isolated from peripheral blood mononuclear cells (PBMCs) despite the presence of HIV-1-specific neutralizing antibodies and possibly CTLs. It is noteworthy that HIV-1 isolates derived from infectious human samples that are known to be pathogenic in the natural host can establish persistent infection in challenged animals. Unlike disease progression after HIV-1 infection of humans, disease progression has been observed in a limited number of chimpanzees to date. Analysis of the immune responses induced by DNA plasmid vaccines in naive chimpanzees has importance major histocompatibility complex (MHC) antigens as well as T-cell receptor antigens, molecularly and biologically conserved cytokines and costimulatory molecules. In addition, HIV-1 infection of chimpanzees is similar to human infection, for understanding the role of this technology in prophylactic vaccine development. For these reasons, we sought to investigate the ability of DNA plasmids to affect HIV- 1 replication in the chimpanzee model.

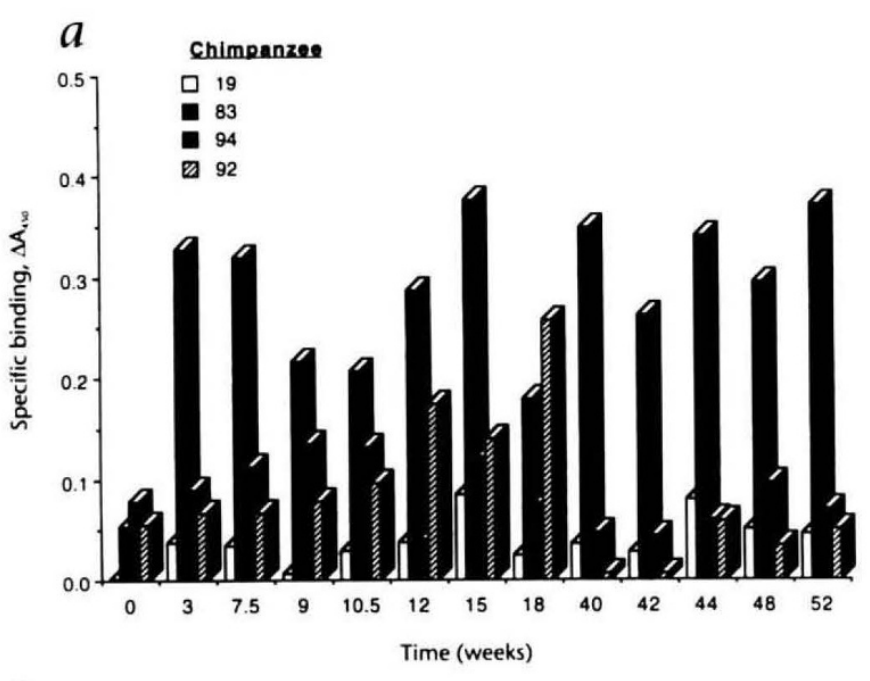

C

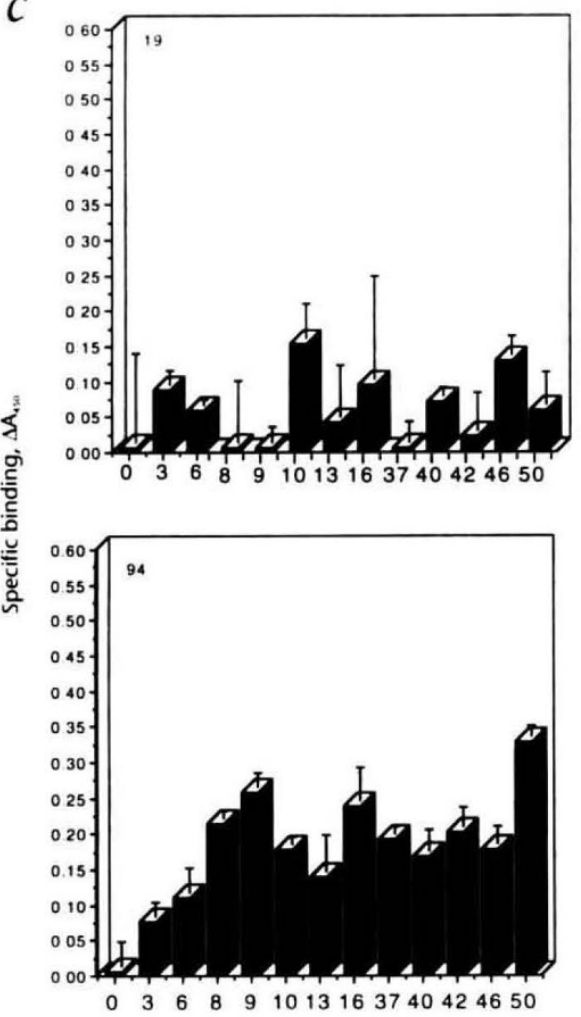

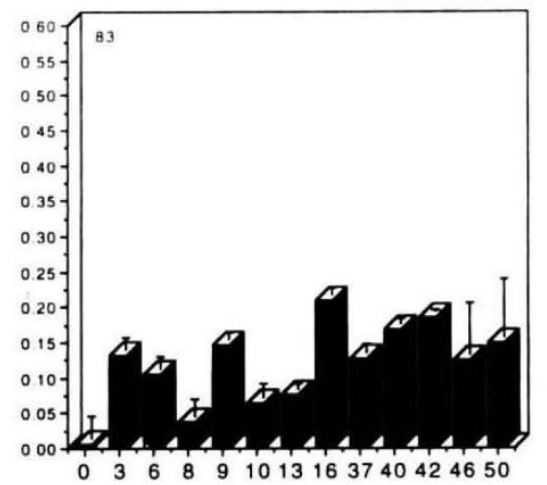

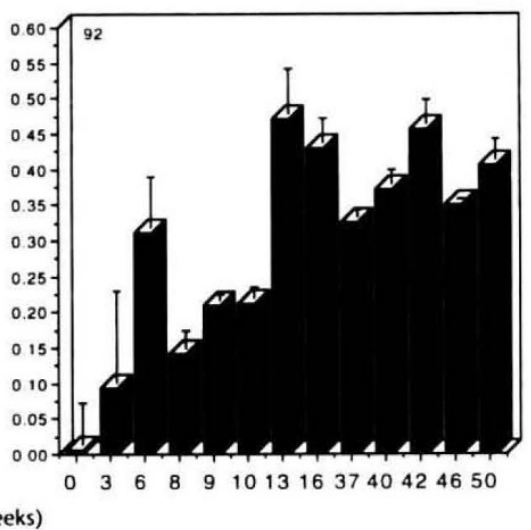

Fig. 2 Antibody responses in chimpanzees immunized with the pCMN160 and $\mathrm{pCgag} / \mathrm{pol}$ or the control vector. Serum samples from HIV-1 negative chimpanzees were diluted $1: 50$ and analyzed for their ability to bind the following: a, recombinant gp $120 ; b$, cyclic V3 loop (AIDS Research and Reference Reagent Program); and $c$, gp41 peptide (amino acids 651-670) (AIDS Research and Reference Reagent Program). 


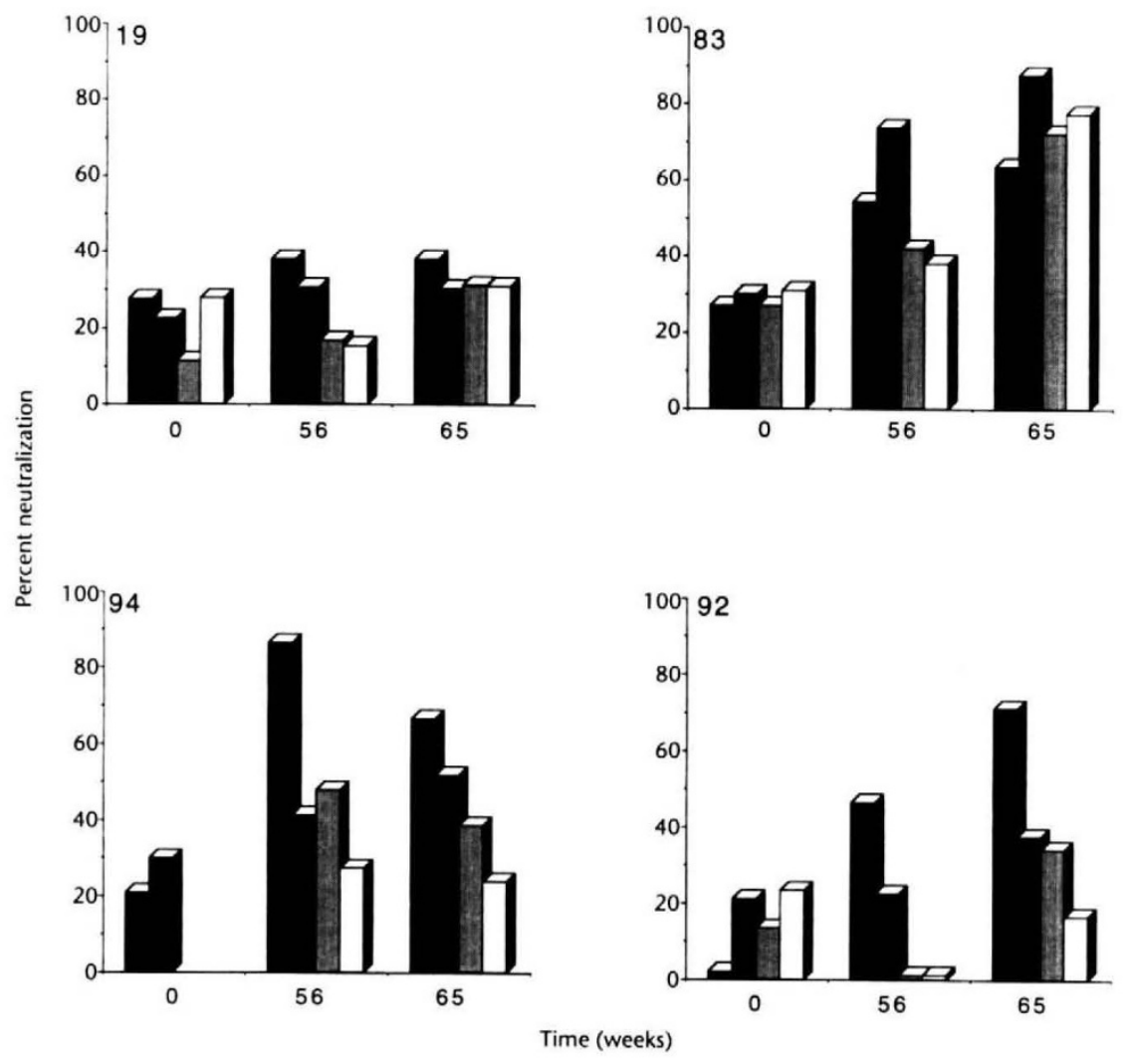

Fig. 3 In vitro neutralization of HIV-1 MN. MT2 cells were infected with $100 \mathrm{TCID}_{50}$. Serum at indicated weeks from immunized chimpanzees was diluted 1:20 (black bar), 1:40 (dark gray bar), 1:80 (light gray bar) and 1:160 (white bar). Standard deviations were within $7 \%$.

\section{Serum binding to HIV-1 proteins and peptides}

We immunized three chimpanzees (two males and one female) as indicated in Fig. 1. A fourth male chimpanzee was immunized with equivalent doses of an identically prepared control vector lacking the HIV-1 gene insert. Both pre- and post-immunization serum samples from the immunized and control chimpanzees were diluted, and binding reactivity to recombinant envelope protein and a number of HIV-1 envelope-derived peptides was measured. The three immunized experimental chimpanzees developed different antibody profiles against recombinant gp120 as well as the HIV-1 MN V3 loop (Fig. 2, $a$ and $b$ ). In addition, chimpanzee 83 demonstrated antibody responses to several peptides at dilution of 1:50 (data not shown), including peptides spanning amino acids $421-440,431-450$ and $471-490$, whereas chimpanzees 94 and 92 responded to the peptide spanning amino acids 471-490. Furthermore, chimpanzees 94 and 92 demonstrated serological responses to a peptide spanning amino acids 651 to 670 (Fig. 2c). This region of gp41 is of interest, as a broadly neutralizing human monoclonal antibody has been characterized that maps to amino acids 651 to 670 (ref. 29). Lowtiter antibody responses to core protein p55 were only detected in the serum of chimpanzee 92 (data not shown). In murine studies, $100 \%$ of the $\mathrm{pCgag} / \mathrm{pol}$ vaccinated animals developed strong cellular responses to Gag/Pol targets, but the majority of animals exhibited low-titer antibody responses to Gag antigens by enzyme-linked immunosorbent assay (ELISA) (J.D.B. et al., unpublished). Therefore, vaccination of chimpanzees with HIV1 DNA constructs induced significant anti-Env antibody responses, but low anti-Gag antibody responses.

\section{Neutralization activity of serum}

The antibodies against HIV- 1 in these DNA vaccinated animals demonstrated neutralizing activity. Serum from chimpanzee 83 , which had exhibited a high serological response to gp120, also demonstrated consistent in vitro neutralizing activity against HIV$1 \mathrm{MN}$ at dilutions of up to 1:160. Serum from chimpanzee 94 and 92 also inhibited infection by homologous strains of HIV-1, although at lower neutralization titers (up of 1:20) (Fig. 3). Serum from the animal vaccinated with the vector control failed to neutralize the HIV-1 strain MN virus stock at any dilution.

\section{Cytotoxic T-lymphocyte response}

We evaluated CTL responses to Gag/Pol- or Env-expressing targets using immortalized EBV-transformed autologous cell lines. We observed induction of CTL activity against Env targets in bulk PBMCs in chimpanzee 94 at multiple time points following vaccination. The other two vaccinated chimpanzees ( 83 and 92) failed to demonstrate CTL activity against targets expressing the Env proteins (Fig. 4a). In addition, both chimpanzees 83 and 94 developed specific CTL responses to targets expressing the HIV-1 Gag/Pol proteins (Fig. $4 b$ ) although 94 exhibited a significantly more sustained response. The CTL responses in the control animal, 19, were negligible to either Env- or Gag/Pol- expressing targets.

\section{Viral challenge}

Chimpanzee 83, which exhibited the most consistent neutralizing antibody profile, chimpanzee 94 , which exhibited the most consistent CTL profile, and the control chimpanzee (19) were challenged with a heterologous, high-dose $\left(250\right.$ ChimpID $\left._{50}\right)$ stock of HIV-1 SF2. Chimpanzee 92 was used as a negative control. Polymerase chain reaction coupled with reverse transcriptase (RT-PCR) (sensitivity of 50 copies $/ \mathrm{ml}^{30,31}$ ) was used to assess viremia and was repeated in triplicate on three separate occasions for each sample (Table 1). As expected, the control animal became infected within 2 weeks of challenge and has remained positive by RT-PCR for the 48 weeks following challenge. In con- 

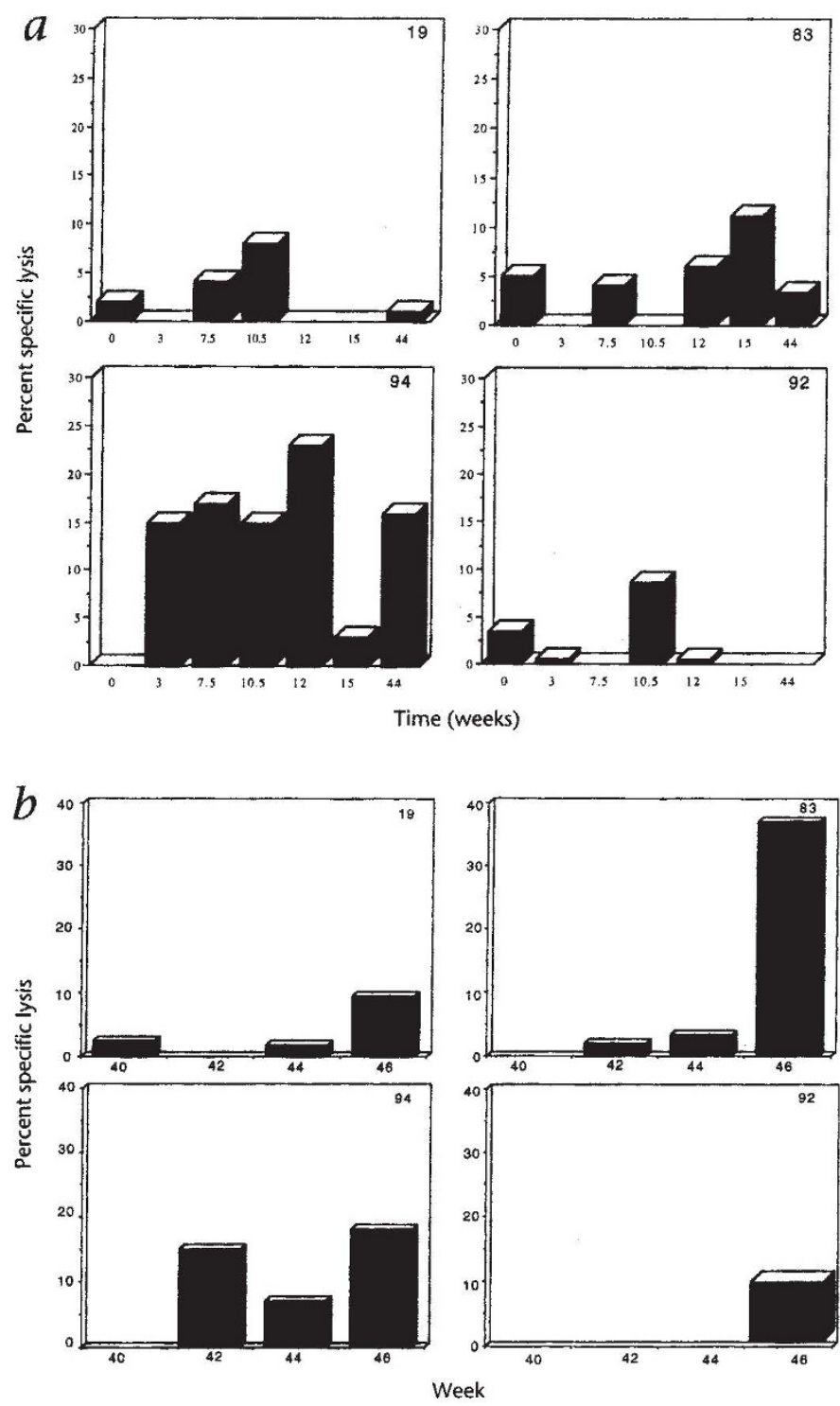

Fig. 4 Cytotoxic T-lymphocyte assay. Percent specific lysis of targets expressing $a$, HIV-1 envelope protein; and $b$, HIV-1 Gag/Pol proteins. Specific lysis is the percent lysis above background lysis of a negative control. Standard deviations were within $7 \%$.

trast, chimpanzees 83 and 94 exhibited a drastically different RTPCR profile following challenge. We observed RT-PCR positivity in chimpanzee 83 at a single time point (week 6) following challenge. This animal has remained negative as assessed by RT-PCR through week 48 of the study. Similarly chimpanzee 94 was RTPCR positive at a single time point (week 8), with no virus detectable during the remainder of the study. Samples from week 6 and 8 were analyzed using the Chiron clinical branched-chain assay (sensitivity 500 copies $/ \mathrm{ml}$ ). The results demonstrated that animal 83 and 94 were both regative for weeks 6 and 8 , whereas the plasma from the control animal (19) had $10^{4}$ particles $/ \mathrm{ml}$ on both weeks 6 and 8 . Additionally, inguinal lymph node biopsies were taken at week 22 and subjected to DNA PCR analysis as described $^{32}$. The tissue from animal 19 was positive, whereas both 83 and 94 , as well as animal 92, were negative. Both humoral and cellular responses were examined post challenge, and viral load was analyzed. Neither immunized chimpanzee 83 or 94 showed boosting in CTLs or antibodies following challenge. CTLs were not detected in the control animal following challenge; western blot analysis was, however, positive. These data support the ability of this vaccination technique to protect chimpanzees from challenge with HIV-1.

\section{CD28 levels following HIV-1 challenge}

Changes in T-cell functions and subsets have been described as a consequence of HIV-1 infection ${ }^{33,34}$. In particular, downregulation of $\mathrm{CD} 28^{*}$ on $\mathrm{CD}^{+} \mathrm{T}$ cells has been associated with progressive infection ${ }^{35}$. CD28 $8^{+}$is expressed on normal $\mathrm{CD}^{+} \mathrm{T}$ cells and most $\mathrm{CD}^{+} \mathrm{T}$ cells and is upregulated through binding of either the B7.1 or B7.2 ligands, which are presented to T cells along with MHC antigen complexes on antigen-presenting cells. This interaction provides a critical costimulatory signal for T-cell activation. Recent studies support the particular importance of the CD28+ligand in HIV immunopathology ${ }^{36}$. CD28 $8^{+}$levels were evaluated in both infected and naive control animals (Table 2). The CD28 ${ }^{+}$ profiles observed in these control chimpanzees duplicated the results observed in humans: CD28 $8^{+}$expression decreased in the infected animals. We next examined the CD28 ${ }^{+}$expression of the experimental chimpanzee PBMCs following challenge (Table 2). Fluorescence-activated cell sorting (FACS) analysis of PBMCs isolated from chimpanzee 19 revealed a $\mathrm{CD} 28^{+}$profile similar to that reported in humans infected with HIV-1. Specifically, significantly lower levels of $\mathrm{CD}^{\circ} 8^{*}$ expression were measured coincident with the animal's infection status. In contrast, PBMCs of chimpanzees 83 and 94 demonstrated CD28+ expression analogous to individuals seronegative for HIV-1 (ref. 37). These data further support the viral load observations.

All animals appeared to be in good health throughout the study as assessed by body weights and clinical observations. Furthermore, there was a lack of redness or tenderness observed in any of the animals at the site of injection, consistent with previous studies ${ }^{24}$.

\section{Discussion}

Of the traditional approaches to vaccination against pathogenic human viruses only live attenuated virus preparations activate both arms of the immune system in a manner similar to that caused by natural infection. However, disease may occur after administration of attenuated vaccines because of viral mutation and reversion to a pathogenic isolate. With these concerns in mind, novel technologies such as DNA vaccination have been examined as viable strategies for the prevention of infection with HIV-1 and other pathogenic human viruses. Indeed, several groups have reported on the induction of specific cellular and humoral immune responses directed against vaccine-encoded antigen $(s)^{13-17}$. Protection has been reported in several murine studies after DNA vaccination ${ }^{18-21}$. In the case of HIV, humoral and cellular responses have been induced in macaques ${ }^{22-24}$ as well as mice $22.25-27$. However, before this report, DNA vaccines had never been shown to induce protective responses in the chimpanzee model $^{28}$.

In the current study, PBMCs isolated from chimpanzee 94 induced both anti-Env and anti-Gag/Pol CTL activity. Serum from the same animal had measurable levels of antibodies to gp 160 as well as low-level neutralizing activity against homologous virus. Chimpanzee 83 demonstrated anti-Gag/Pol CTL activity and consistently high antibody reactivity to HIV-1 envelope, as well as neutralizing antibodies to homologous HIV-1. Chimpanzee 92 failed to demonstrate specific CTL activity above background 
Table 1 RT.PCR results from chimpanzees challenged with 250 ChimpID $_{50}$ of HIV-1 strain SF2

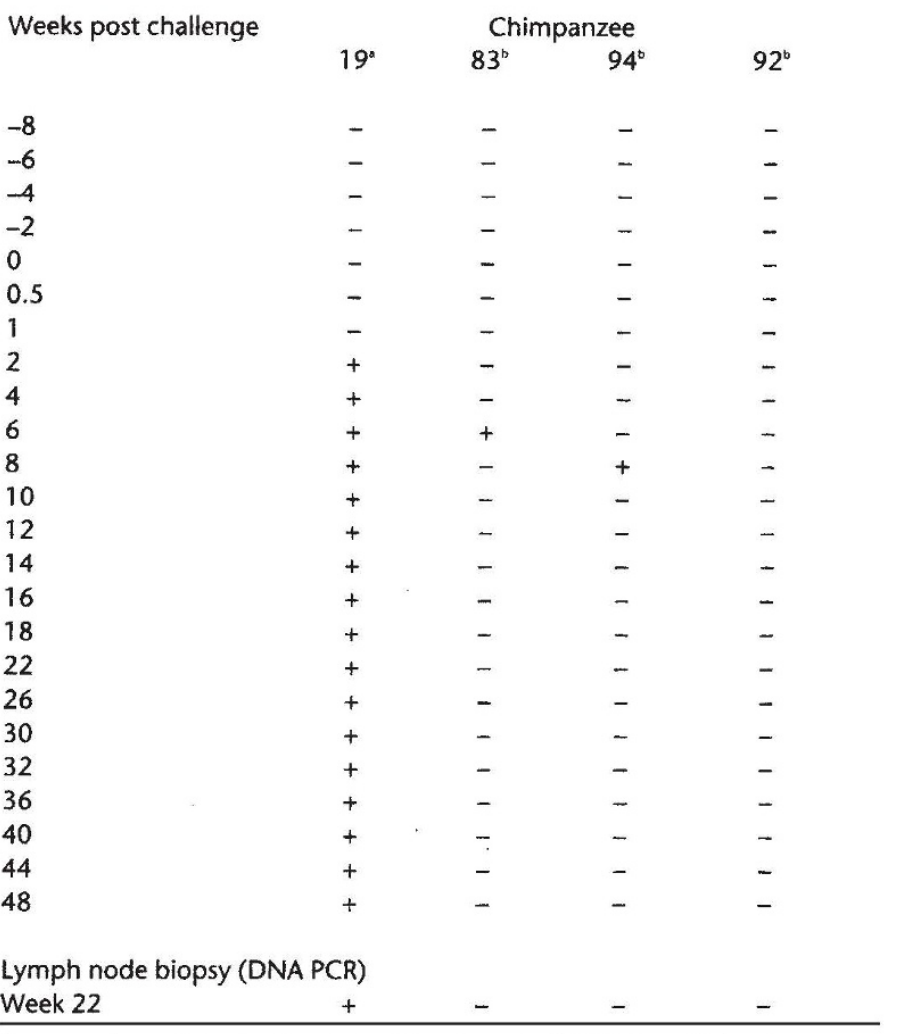

Each sample was tested and evaluated three times by RT-PCR. In addition plasma was tested by Chiron's branched-chain DNA assay. Chimpanzee 83 and 94 by this assay were negative at weeks 6 and 8 as well as at other tested time points. However, chimpanzee 19 demonstrated $>10^{4}$ viral particles $/ \mathrm{ml}^{3}$ of plasma at the same time points. "Immunized with control vector. "Immunized with vectors expressing HIV-1 Env and Gag/Pol.

levels of $10 \%$ at any time, but antibodies to HIV-1 envelope and neutralizing antibodies to homologous HIV-1 were measurable in the serum. Although specific anti-HIV responses were induced in both protected animals, no clear correlates of protection could be determined. Because chimps are outbred, they have broad humoral and cellular immune responses, similar to those of humans. Nonetheless, widely different profiles of immune responses resulted in protection from high-dose challenge, suggesting that protection may be attainable through a variety of immune mechanisms either alone or in combination. Previous reports $^{38,39}$ have strongly suggested that limiting viral replication at the outset of infection is likely to have a dramatic impact on disease progression in an infected individual. At a minimum, the present study demonstrates the effect of this apparently well tolerated approach to control viral replication in vivo and to interrupt the establishment of persistent infection. The further evaluation of this technology for the production of immuno-

Table 2 Expression of CD28 on the cell surface

$$
\text { HIV-1-positive controls }
$$

$$
\text { HIV-1-negative control }
$$

$\begin{array}{ccccccccc}1 & 2 & 3 & 4 & 5 & 6 & 7 & 8 & 9 \\ 26.6 & 31.7 & 15.5 & 33.4 & 30.9 & 35.7 & 53.3 & 61.0 & 65.7\end{array}$

genic DNA expression cassettes to control HIV-1 replication is worth cautious consideration.

\section{Methods}

Animals. The study was performed in the spirit of the Good Laboratory Practice regulations and standard operating procedures of Coulston Foundation White Sands Research Center. Furthermore, the study was conducted in accordance with requirements as specifically stated in Section 3.81 of the Animal Welfare Act (9CFR, Ch. 1).

Plasmids. pCMN160 is an expression cassette coding for the envelope and Rev proteins of HIV-1 strain MN. These genes are under the control of the CMV promoter, followed by a polyadenylation region. pCgag/pol is an expression cassette coding for the Gag/Pol proteins of HIV-1 strain IIIB. Plasmids were formulated as previousty described ${ }^{24}$. Samples were taken every 1.5 weeks to week 24 at which point the animals were monitored every 2 weeks.

Antibody analysis. A recombinant envelope and a subset of peptides spanning possibly important regions of the envelope protein were analyzed by ELISA. ELISA analysis was performed by modifications of previously described methods 6 . Briefly, recombinant gp 120 based on the MN sequence (purchased from Immununodiagnostics, Bedford, MA) was resuspended in $1 \times$ PBS to a concentration of $0.5 \mu \mathrm{g} / \mathrm{ml}$. The gp 120 preparation $(50 \mu \mathrm{l}, 2.5$ ng) was incubated in each of the wells overnight at $4{ }^{\circ} \mathrm{C}$. For analysis of peptides a concentration of $10 \mu \mathrm{g} / \mathrm{ml}$ in a volume of $50 \mu \mathrm{l}$ was used. Plates were then rinsed with washing buffer $(0.45 \% \mathrm{NaCl}$ in deionized water containing $0.05 \%$ Tween 20 ) and blocked with blocking buffer ( $5 \%$ nonfat dry milk in PBS $+1 \%$ BSA $+0.05 \%$ Tween 20 ) for 2 hours at $37^{\circ} \mathrm{C}$. Serum samples were then diluted in dilution buffer ( $5 \%$ nonfat dry milk in PBS $+0.05 \%$ Tween 20) at the appropriate dilutions and incubated in duplicate or triplicate in recombinant protein coated plates for $1 \mathrm{~h}$ at $37^{\circ} \mathrm{C}$, washed and then incubated for $1 \mathrm{~h}$ at $37^{\circ} \mathrm{C}$ with a goat anti-human lg-horseradish peroxidase conjugate (Sigma Chemical Co.) diluted in dilution buffer at the concentration suggested by the manufacturer. After extensive washing the plates were developed with 3,3',5,5'-tetramethylbenzidine dihydrochloride substrate $(100 \mu \mathrm{g} / \mathrm{ml})$, the reaction was stopped with $2 \mathrm{M} \mathrm{H}_{2} \mathrm{SO}_{4}$ and color development was quantified at $450 \mathrm{~nm}$. Two human HIV-1 seronegative serum samples were used as controls, and BSA coated wells were used as negative binding control wells in these assays. Specific binding (absorbance at $450 \mathrm{~nm}$ ) was calculated by subtracting $A_{450}$ values from serum samples bound to BSA (that is, control) from $A_{450}$ values from serum samples bound to gp120; that is, experimental wells ( $A_{450}$ experimental $-A_{450}$ control).

Neutralization assay. The ability of serum to neutralize viral infection in vitro was assessed according to described methods ${ }^{40}$. Supernatant, $50 \mu 1$ containing $100 \mathrm{TCID}_{30}$ of HIV-1/MN, was preincubated with $50 \mu \mathrm{l}$ of serial dilutions of experimental or control chimp serum and added to $3 \times 10^{4} \mathrm{MT}$ 2 target cells $(100 \mu \mathrm{l})$. As an internal control we used chimpanzee's positive and negative serum and a mixture of four serum samples from HIV-1-positive and -negative donors. The infection of cells was determined by the presence of syncitia after $48 \mathrm{~h}$ of incubation. Neutralization titers above $50 \%$ were scored as positive. The percent of neutralization was determined using the following formula:

$100 \%$ - Number of experimental syncytia (cells + virus + serum)/ Number of control syncytia (cells + virus) $\times 100 \%$

Cytotoxic T-lymphocyte assay. A standard $5-\mathrm{h}{ }^{51} \mathrm{Cr}$ release $\mathrm{CTL}$ assay was performed on PBMCs from the inoculated and control chimpanzees. The preparation of stimulators and effectors has been previously described in detail ${ }^{24}$. Immortalized lymphoblastoid cell lines (LCLs) were established by infecting PBMCs with Epstein-Barr virus. These cell lines were then used as stimulators. Briefly, LCLs were infected overnight with a recombinant vaccinia virus (VMN462) that expressed gp 160 from HIV-1 strain MN. Before use, the infected cells were fixed with $0.1 \%$ gluteraldehyde and blocked with a $0.1 \mathrm{mM}$ glutamine solution. The fixed cells were incubated with the
Challenged animals

$\begin{array}{ccc}19 & 83 & 94 \\ 41.5 & 67.0 & 64.6 \\ y . \text { Washed cells were an } \\ \text { antibody (PharMingen) }\end{array}$

Fresh PBMCs were prepared by standard Ficoll-Hypaque centrifugation and washed extensively. Washed cells were analyzed by FACS for determination of CD28 levels using the well characterized 9.3 monoclonal antibody (PharMingen) as described in the Methods section. The PBMCs were taken from HIV-1-infected chimpanzees or uninfected chimpanzees or were collected at 20 weeks post challenge in the challenged animal study. 
freshly isolated PBMCs (effectors) for stimulation. After 3 days of stimulation another batch of LCLs were incubated overnight with VMN462. These cells were labeled with ${ }^{31} \mathrm{Cr}$ and used as target cells. Cells incubated with the a control recombinant vaccinia were used as targets to provide background levels of lysis.

Viral challenge stock. The SF2 viral challenge stock was titered in chimpanzees in vivo and was the generous gift of S.M. Nigida (National Cancer Institute).

Reverse transcriptase-PCR. RNA preparation. RNA was prepared in accordance with manufacturer's protocol (Biotecx Laboratories, Friendswood, TX) using the "Ultra-spec 3" RNA isolation system with a few internal modifications. Briefly, serum $(300 \mu$ l) was mixed with $1500 \mu$ lextraction buffer (Biotecx, BL-27200) followed by the addition of $200 \mu \mathrm{l}$ of chloroform and incubated at $4{ }^{\circ} \mathrm{C}$ for $5 \mathrm{~min}$. Proteins were then removed by centrifuging at $12,000 \mathrm{~g}\left(4^{\circ} \mathrm{C}\right)$ for $15 \mathrm{~min}$. From this, $800 \mu \mathrm{l}(4 / 5)$ of the aqueous layer was transferred to a new $2.0 \mathrm{ml}$ Eppendorf tube containing $1 \mu \mathrm{l}(5 \mu \mathrm{g} / \mu \mathrm{l})$ of glycogen (Ambion, Austin, TX) as a carrier, and the RNA was precipitated with a final concentration of $0.5 \mathrm{M}$ ammonium acetate (ABI, Columbia, $M D$ ) and equal volume of isopropanol to aqueous solution and stored overnight at $-21^{\circ} \mathrm{C}$. Precipitated RNA is collected at $14,000 \mathrm{~g}\left(4^{\circ} \mathrm{C}\right)$ for 15 $\mathrm{min}$, and the remaining pellet is washed with $75 \%$ ethanol, pelleted (same) for $5 \mathrm{~min}$, vacuum dried, and resuspended in $20 \mu \mathrm{l}$ of diethyl pyrocarbonate (DEPC)-treated $\mathrm{dH}_{2} \mathrm{O}$ containing RNase inhibitor $(1 \mathrm{U} / \mu \mathrm{l}$, Perkin-Elmer, Norwalk, $\mathrm{CT}$ ). All RNA were stored at $-80^{\circ} \mathrm{C}$.

Reverse transcription reaction. Synthesis of CDNA and ensuing PCR amplification(s) were made using the Perkin-Elmer Cetus DNA Thermal Cycler 480, as well as internal optimization of the GeneAmp RNA PCR kit reagents as described ${ }^{34}$. CDNA synthesis used HIV-1 extracted RNA $(1.5 \mu \mathrm{I}$ of $20 \mu \mathrm{l})$ and the following reaction preparation from the Perkin-Elmer RNA PCR kit to obtain $2.5 \mathrm{mM} \mathrm{MgCl}_{2}, 1 \times$ PCR II buffer $(50 \mathrm{mM} \mathrm{KCl}, 10 \mathrm{mM}$ Tris- $\mathrm{HCl}$, pH 8.3), $1 \mathrm{mM}$ dNTPs, $1 \mathrm{U} / \mu \mathrm{l}$ RNase inhibitor, and $2.5 \mathrm{U} / \mu \mathrm{l}$ MMLV-RT, plus 25 pmol of the HIV-1 specific LTR-gag region external antisense primer AV13 5'-CTCCGAATCGTTCTACCTCCCTGCTTCCCC-3' (antisense NT 895-924 of $\mathrm{HXB2})^{30}$. The synthesis was brought to a final volume of $10 \mu \mathrm{l}$ with sterile $\mathrm{H}_{2} \mathrm{O}$ and overlaid with $40 \mu \mathrm{l}$ of mineral oil (Perkin-Elmer) and a reverse transcription run of $10 \mathrm{~min}$ at $23^{\circ} \mathrm{C}, 60 \mathrm{~min}$ at $42^{\circ} \mathrm{C}, 10 \mathrm{~min}$ at $99^{\circ} \mathrm{C}$, and finally quickly chilled on ice.

$P C R$ and nested $P C R$ amplification. To the above HIV- 1 CDNA product $(10 \mu \mathrm{I})$, a $30-\mu$ reaction volume containing $1 \times$ PCR II buffer $(10 \mathrm{mM}$ Tris- $\mathrm{HCl}, \mathrm{pH}$ $8.3,50 \mathrm{mM} \mathrm{KCl}$ ), $1.5 \mathrm{mM} \mathrm{MgCl}_{2}, 25$ pmol external sense primer AV 10 5'-TGTGACTCTGGTAACTAGAGATCCCTCAGA-3' (sense NT 574-603 of $\mathrm{HXB2}, \mathrm{AC} \mathrm{K03455})^{30}$ of the LTR-gag region, and $\mathrm{dH}_{2} \mathrm{O}$ (sterile) was underlaid and a "hot start" reaction was initiated.

The mixture was run for one cycle of $2 \mathrm{~min}$ at $96^{\circ} \mathrm{C}$, followed by $10 \mathrm{~min}$ at $80^{\circ} \mathrm{C}$ with a $1.25 \mathrm{U} / 50 \mu \mathrm{l}$ AmpliTaq DNA polymerase (Perkin-Elmer) in sterile $\mathrm{dH}_{2} \mathrm{O}(10 \mu \mathrm{l}$ total) being underlaid $5 \mathrm{~min}$ into the latter temperature sequence for a total PCR sample volume of $50 \mu \mathrm{l}$ before the amplification sequence cycles (below).

Reaction conditions on the 480 DNA Thermal Cycler for the external PCR were as follows: 25 cycles of $1 \mathrm{~min}$ at $94^{\circ} \mathrm{C}, 1.5 \mathrm{~min}$ at $70^{\circ} \mathrm{C}$, and $1 \mathrm{~min}$ at $72^{\circ} \mathrm{C}$. For the internal PCR (N.PCR below), conditions were 25 cycles of 1 min at $94^{\circ} \mathrm{C}, 1.5 \mathrm{~min}$ at $47^{\circ} \mathrm{C}$, and $1 \mathrm{~min}$ at $72^{\circ} \mathrm{C}$. Additionally, in both cases, the reactions were finished off with a $4 \mathrm{~min}$ at $72{ }^{\circ} \mathrm{C}$ extension and $>5$ min at $4{ }^{\circ} \mathrm{C}$ soak. All PCR products stored at $-21^{\circ} \mathrm{C}$. N-PCR was prepared using $1 \mu \mathrm{l}(1 / 50$ th) of the RT-PCR product and a master mix from PerkinElmer GeneAmp RNA PCR kit reagents for a $1 \times$ PCR II buffer $(10 \mathrm{mM}$ Tris$\mathrm{HCl} \mathrm{pH} \mathrm{8.3,50} \mathrm{mM} \mathrm{KCl),} 1 \mathrm{mM}$ dNTPs, $1.5 \mathrm{mM} \mathrm{MgCl}_{2}$, sterile $\mathrm{dH}_{2} \mathrm{O}$, and $1.25 \mathrm{U} / 50 \mu \mathrm{l}$ AmpliTaq DNA polymerase, plus $10 \mathrm{pmol}$ of HIV-1 internal LTR-gag region primer AV11 5'-TCTAGCAGTGGCGCC-3' (sense NT 628642 of HXB2), and AV1 2 5'-GACGCTCT CCCACCC-3' (antisense NT 791805 of $H X B 2)^{30}$ for a $50-\mu 1$ reaction volume. Samples were again overlaid with $40 \mu \mathrm{l}$ mineral oil and the above N-PCR reaction conditions were initiated. A commercially available HIV-1-positive control plasmid DNA (PerkinElmer, N808-0016) was simultaneously tested during PCR and N-PCR reactions using the same external and internal primer sets. As it was DNA, no reverse transcription was performed. All PCR products were analyzed on a $4 \%$ agarose $/ 1 \times$ TBE gel with a sample load of $10 \mu \mathrm{l}$, electrophoresed for $60 \mathrm{~min}$ at $150 \mathrm{~V}$, followed by ethidium bromide staining.

FACS analysis. Cells were isolated as described above ${ }^{24}$ by Ficoll-Hypaque and washed twice in FACS buffer ( $\left.1 \times \mathrm{PBS}, 1 \% \mathrm{BSA}, 0.1 \% \mathrm{NaN}_{3}\right)$. The cells were incubated at a concentration of $3 \times 10^{5}$ cells with anti-CD28 conjugated antibody (33745X, PharMingen, San Diego, CA) for $1 \mathrm{~h}$ at $4{ }^{\circ} \mathrm{C}$ in the dark. The cells were washed twice in FACS Buffer and fixed in $0.5 \mathrm{ml} 2 \%$ Paraformaldehyde. The cells were analyzed on EPICS XL flow cytometer (Coulter Corp., Hialeah, FL).

\section{Acknowledgments}

We would like to thank Alex Traevino for his expertise with the RT-PCR assays. We would also like to thank Michael Marr and Michael Merva for their extensive help in moving this project forward. This work was supported in part by grants from the National Institutes of Health including a Strategic Program in Innovative Research and AIDS Treatment (SPIRAT) grant to D.B.W.

\section{RECEIVED 21 NOVEMBER 1996; ACCEPTED 4 MARCH 1997}

1. Haynes, B.F., Pantaleo, G. \& Fauci, A.S. Toward an understanding of the correlates of protective immunity to HIV infection. Science 271, 324-328 (1996).

2. Pantaleo, G. et al. Studies in subjects with long-term nonprogressive human immunodeficiency virus infection. N. Engl. I. Med. 332, 209-216 (1995)

3. Rinaldo, C. et al. High levels of anti-human immunodeficiency virus type 1 (HIV-1) memory cytotoxic T-lymphocyte activity and low viral load are associated with lack of disease in HIV-1 infected long-term nonprogressors. /. Virol. 69, 5838-5842 (1995).

4. Rowland-Jones, S. et al. HIV-specific cytotoxic T-cells in HIV-exposed but uninfected Gambian women. Nature Med. 1, 59-64 (1995)

5. Rowland-jones, S., Nixon, D. \& Aldhous, M. HIV-specific cytotoxic T-cell activity in an HIV-exposed but uninfected infant. Lancet 341, 860-861 (1993).

6. Ugen, K.E. et al. Vertical transmission of immunodeficiency virus type 1 : Seroreactivity by maternal antibodies to the carboxy region of the gp41 envelope. J. Infect. Dis. 175, 63-69 (1997).

7. Ugen, K.E. et al. Vertical transmission of human immunodeficiency virus (HIV) infection: Reactivity of maternal sera with glycoprotein 120 and 41 peptides from HIV type 1. 1. Clin. Invest. 89, 1923-1930 (1992).

8. Rossi, P. et al. Presence of maternal antibodies to human immunodeficiency virus 1 envelope glycoprotein gp1 20 epitopes correlates with the uninfected status of children born to seropositive mothers. Proc. Natl. Acad. Sci. USA 86, 8055-8058 (1989)

9. Goedert, J. et al. Mother-to-infant transmission of human immunodeficiency virus type 1: Association with prematurity or low anti-gp120. Lancet 2, 1351-1354 (1989).

10. Dubensky, T., Campell, B. \& Villarreal, L. Direct transfection of viral and piasmid DNA into the liver of spleen of mice. Proc. Natl. Acad. Sci. USA 81, 7529-7533 (1984).

11. Raz, E. et al. Systemic immunological effects of cytokine genes injected into skeletal muscle. Proc. Nati. Acad. Sci. USA 90, 4523 (1993).

12. Wolff, J.A. et al. Direct gene transfer into mouse muscle in vivo. Science 247, 1465-1468 (1990).

13. Wang, B. et al. Immunization by direct DNA inoculation induces rejection of tumor cell challenge. Hum. Gene Ther. 6, 407-418 (1995).

14. Ulmer, J.B. et al. Heterologous protection against influenza by injection of DNA encoding a viral protein. Science 259, 1745-1749 (1993).

15. Tang, D.C., Devit, M. \& Johnston, S.A. Genetic immunization is a simple method for eliciting an immune response. Nature 356, 152-154 (1992).

16. Michel, M.L. et al. DNA-mediated immunization to the hepatitis $B$ surface antigen in mice: Aspects of the humoral response mimic hepatitis B viral infection in humans. Proc. Natl. Acad. Sci. USA 92, 5307-5311 (1995).

17. Lowrie, D.B., Tascon, R.E., Colston, M.J. \& Silva, C.L. Towards a DNA vaccine against tuberculosis. Vaccine 12, 1537-1540 (1994).

18. Barry, M., Lai, W. \& Johnston, S. Protection against mycoplasma infection using expression-library immunization. Nature 377, 632-635 (1995).

19. Fynan, E.F., Webster, R.G., Fuller, D.H. \& Haynes, J.R. DNA vaccines: Protective immunizations by parental, mucosal and gene-gun inoculations. Proc. Natl. Acad. Sci. USA 90, 11478-11482 (1993).

20. Wang, B. et al. DNA inoculation induces protective in vivo immune responses against ceflular challenge with HIV-1 antigen-expressing cells. AIDS Res. Hum. Retroviruses 10 (Suppl. 2), \$35-S41 (1994).

21. Wang, B. et al. DNA inoculation induces cross clade anti-HIV-1 responses. Ann. NY Acad. Sci. 772, 186-197 (1995).

22. Wang, B. et al. Induction of humoral and cellular immune responses to the human immunodeficiency virus type 1 in non-human primates. Virology 221, 102-112 (1995).

23. Wang, B. et al. Gene inoculation generates immune responses against human immunodeficiency virus type 1. Proc. Natl. Acad. Sci. USA 90, 4156-4160 (1993).4

24. Boyer, J.D. et al. In vivo protective anti-HIV immune responses in non-human primates through DNA immunization. J. Med. Primatol. 25, 242-250 (1996). 
25. Lu, S., Santoro, I.C., Fuller, D.H., Haynes, J.R. \& Robinson, H.L. Use of DNAs expressing HIV-1 env and non-infectious HIV-1 particles to raise antibody responses in mice. Virology 209, 147-154 (1995).

26. Haynes, I.R., Fuller, D.H. Eisenbraun, M.D. Ford, M.J. \& Pertmer, T.M. Accell( particle-mediated DNA immunization elicits humoral, cytotoxic and protective responses. AIDS Res. Hum. Retroviruses 10 (Suppl. 2), S43-S45 (1994).

27. Okuda, K. et at. Induction of potent humoral and cell-mediated immune responses following direct injection of DNA encoding the HIV type 1 env and rev gene products. AIDS Res. Hum. Retroviruses 11, 933-943 (1995).

28. Lu, S. et al. Simian Immunodeficiency virus DNA vaccine trial in macaques. J. Virol. 70, 3978-3991 (1996).

29. Muster, T. et al. A conserved neutralizing epitope on gp41 of human immunodeficiency virus type 1. I. Virol. 11, 6642-6647 (1993).

30. Vandamme, A.-M. Polymerase chain reaction (PCR) as a diagnostic tool in HIV infection. Verh. K. Acad. Geneeskd. Belg. 3, 231-265 (1994).

31. Vandamme, A.-M. et al. Detection of HIV-1 RNA in plasma and serum samples using the NASBA amplification system compared to RNA-PCR. $\int$. Virol. Methods $\mathbf{5 2}$. 121-132 (1995)

32. Shibata, R. et al. Resistance of previously infected chimpanzees to successive chal. lenges with a heterologous intraciade $B$ strain of human immunodeficiency virus type 1. I. Virol. $70,4361-4369$ (1996).
33. Lane, H.C., Depper, J.M., Greene, W.C., Whialen, G., Waidmann, T.A. \& Fauci, A.D. Qualitative analysis of immune function in patients with the acquired immunodeficiency syndrome: Evidence for a selective defect in soluble antigen recognition. $N$. Engl. f. Med. 313, 79-84 (1985).

34. Gruters, R.A. et al. Selective loss of T cell functions in different stages of HIV infection. Eur. I. Immunol. 20, 1038-1044 (1990).

35. Vingerhoets, J.H. et al. Increased cytolytic T lymphocyte activity and decreased B7 responsiveness are associated with $\mathrm{CD} 28$ down-regulation on $\mathrm{CD} 8+\mathrm{T}$ cells from HIV-infected subjects. Clin. Exp. Immun. 100, 425-433 (1995).

36. Levine, B.L. et al. Antiviral effect and ex vivo CD4 T cell proliferation in HIV-positive patients as a results of CD28 costimulation. Science 272, 1939-1943 (1996).

37. Brinchmann, J.E. et al. Expression of costimulatory molecule CD28 on T cells in human immunodeficiency virus type $?$ infection: Functional and clinical correlations. J. Infect. Dis. 169, 730-738 (1993).

38. Ho, D.D. et al. Rapid turnover of plasma virions and CD4 ${ }^{*}$ lymphocytes in HIV-1 infection. Nature 373, 123-126 (1995).

39. Wei, X. et al. Viral dynamics in human immunodeficiency virus type 1 infection. Nature 373, 117-122 (1995)

40. Montifiori, D.C., Robinson, W.E., Schiffmann, S.S. \& Michell, W.M. Evaluation of antiviral drugs and neutralizing antibodies to human immunodeficiency virus by a rapid and sensitive microtiter infection assay. . . Clin. Invest. 6, 231-235 (1988). 